2016-01

Novel tri- and tetra-unsaturated highly branched isoprenoid (HBI) alkenes from the marine diatom Pleurosigma intermedium

\title{
Brown, Thomas
}

http://hdl.handle.net/10026.1/4927

10.1016/j.orggeochem.2015.11.008

ORGANIC GEOCHEMISTRY

Elsevier BV

All content in PEARL is protected by copyright law. Author manuscripts are made available in accordance with publisher policies. Please cite only the published version using the details provided on the item record or document. In the absence of an open licence (e.g. Creative Commons), permissions for further reuse of content should be sought from the publisher or author. 
Disclaimer: This is a pre-publication version. Readers are recommended to consult the full published version for accuracy and citation.

1 Novel tri- and tetra-unsaturated highly branched isoprenoid (HBI) alkenes

2 from the marine diatom Pleurosigma intermedium.

3

4 Thomas A. Brown, Simon T. Belt*.

5

6 School of Geography, Earth and Environmental Sciences, University of

7 Plymouth, Drake Circus, Plymouth, Devon PL4 8AA, UK

8

$9 \quad$ *Author for correspondence. Tel.: +44 (0)1752 584959;

E mail address: sbelt@plymouth.ac.uk (Simon Belt).

ABSTRACT

Two previously uncharacterised $\mathrm{C}_{25}$ highly branched isoprenoid (HBI) alkenes

have been identified in a laboratory culture of the diatom Pleurosigma intermedium and their structures determined using a combination of NMR spectroscopy and gas chromatography-mass spectrometry (GC-MS). These

17 new tri- and tetra-unsaturated HBI alkenes are stereoisomers of previously characterised HBIs, with a $Z$ stereochemistry for the C5-C6 double bond in each case. HBIs with an isomeric (E/Z) C5-C6 double bond and with 1-4 double bonds, in total, have extremely similar mass spectra and a consistent

21 difference in retention index ( $\triangle \mathrm{RI} 28)$, with a $Z$ before $E$ elution order in all 22 cases.

23 Keywords: highly branched isoprenoid; alkene; diatom; Pleurosigma 


\section{Introduction}

$\mathrm{C}_{25}$ highly branched isoprenoid (HBI) alkenes are common components of marine and lacustrine sediments worldwide and are biosynthesised by certain diatoms mainly belonging to the genera Haslea, Rhizosolenia, Pleurosigma and Berkeleya (Volkman et al., 1994; Belt et al., 1996, 2000; Sinninghe Damsté et al., 1999; Grossi et al., 2004; Brown et al., 2014). $\mathrm{C}_{25}$ HBIs contain between one and six double bonds (DB) and occur in a number of regio- and stereo-isomeric forms. Individual structures have been established mainly through diatom culturing and analysis of purified extracts using NMR spectroscopy (e.g. Belt et al., 1996, 2000; Sinninghe Damsté et al., 1999; Grossi et al., 2004; Brown et al., 2014). Here, we identify two novel $\mathrm{C}_{25} \mathrm{HBI}$ isolated from a culture of the diatom Pleurosigma intermedium and report their structures following analysis of partially purified extracts using NMR spectroscopy and gas chromatography-mass spectrometry (GC-MS).

\section{Experimental}

P. intermedium (RA120910 P1B3) was obtained from the Roscoff Culture Collection (http://roscoff-culture-collection.org/) and cultured in the laboratory $\left(15^{\circ} \mathrm{C}, 100 \mu \mathrm{mol} \mathrm{m}{ }^{-2} \mathrm{~s}^{-1}, 14 / 10 \mathrm{~L} / \mathrm{D}\right.$ cycle in $\mathrm{f} / 2$ enriched water). After 21 days, cells were filtered (GF/F), sonicated (DCM; $5 \mathrm{ml})$, re-filtered through a small plug cotton wool, dried $\left(\mathrm{N}_{2}\right)$, then partially purified using column chromatography $\left(\mathrm{SiO}_{2}\right)$. The hydrocarbon fractions (hexane; $5 \mathrm{ml}$ ) were analysed by GC-MS using a Hewlett-Packard 5890 Series II gas chromatograph, fitted with a $30 \mathrm{~m}$ fused silica $\mathrm{HP}_{5 \mathrm{~ms}}$ column $(0.25 \mathrm{~mm}$ i.d., 
$0.25 \mu \mathrm{m}$ film) coupled to a 5970 Series Mass Selective Detector (MSD) (Brown et al., 2014). For further separation of HBIs we used Ag-ion chromatography (Supelco discovery ${ }^{\circledR}$ Ag-Ion; $0.1 \mathrm{~g}$ ) to obtain saturated hydrocarbons (hexane; 3 ml), HBI I (acetone/DCM; 50/50; $5 \mathrm{ml}$ ) and HBI III (acetone; $5 \mathrm{ml}$ ). NMR data were obtained using a JEOL ECP-400 NMR spectrometer with chemical shifts measured relative to those of $\mathrm{CDCl}_{3}\left({ }^{1} \mathrm{H}: 7.24 \mathrm{ppm} ;{ }^{13} \mathrm{C}: 77.0 \mathrm{ppm}\right)$.

\section{Results and discussion}

Extraction of a culture of $P$. intermedium, followed by a two-stage purification (see Experimental) yielded sufficient quantities of two HBI alkenes for analysis by GC-MS and NMR spectroscopy. These HBIs were identified as tri- and tetra-unsaturated $\mathrm{C}_{25} \mathrm{HBI}$ on the basis of the $\mathrm{M}^{+} .(\mathrm{m} / z$ 346 and 344, respectively) in their mass spectra (Fig. 1).

The ${ }^{1} \mathrm{H}$ NMR spectrum of the HBI triene (I; Fig. 1) exhibits multiplets at 5.63 and $4.89 \mathrm{ppm}$ (Table 1) characteristic of a vinyl moiety at C23-C24, a structural feature found in virtually all previously reported HBI alkenes (Belt et al., 1996, 2000; Sinninghe Damsté et al., 1999; Grossi et al., 2004; Brown et al., 2014). Two further alkene protons (H5 and H9) could also be identified from their distinctive chemical shifts and multiplicities (Table 1). Alternative positions for the two tri-substituted DB at $\mathrm{C} 2-\mathrm{C} 3$ or $\mathrm{C} 13-\mathrm{C} 14$ could be discounted due to the observation of two isopropyl groups at 0.85 and $0.84 \mathrm{ppm}$, totalling $12 \mathrm{H}$ (Table 1). The ${ }^{13} \mathrm{C}$ NMR spectrum of triene I was also consistent with the presence of a vinyl group (C23-C24), two tri-substituted DB (C5-C6, C9-C10) two isopropyl $\mathrm{CH}_{3}(\mathrm{C} 1 \& \mathrm{C} 16, \mathrm{C} 15 \& \mathrm{C} 19)$ and three further $\mathrm{CH}_{3}$ groups 
73 (C17, C18, C25) (see Table 1 for details). However, since a $\mathrm{C}_{25}$ triene with DB

74 at $\mathrm{C} 5-\mathrm{C} 6, \mathrm{C} 9-\mathrm{C} 10$ and $\mathrm{C} 23-\mathrm{C} 24$ has been characterised previously (Wraige et 75 al., 1999), but with a different retention index (RI) to that of the triene 76 investigated here, we believed that the latter likely represented a stereoisomer 77 of the former, which has known $E$ stereochemistry for both DB (structure II; 78 Fig. 1; Wraige et al., 1999). Confirmation of this, and identification of the stereochemistry for each DB, was achieved by further inspection of the ${ }^{1} \mathrm{H}$ and ${ }^{13} \mathrm{C}$ NMR data. Specifically, it has been shown previously that the ${ }^{13} \mathrm{C}$ chemical shifts for $\mathrm{C} 11$ and $\mathrm{C} 18$ in other $\mathrm{C}_{25} \mathrm{HBI}$ trienes are particularly characteristic of the stereochemistry at C9-C10, with C11 occurring at ca. 40 ppm and 32 ppm for the $E$ and $Z$ isomers, respectively, while C18 appears at 15.7 ppm (E) and $23.5 \mathrm{ppm}(Z)$ (Belt et al., 2000). Since C11 for the triene in our $P$. intermedium culture appears at $40.1 \mathrm{ppm}$, with a further resonance at 16.4 ppm attributed to $\mathrm{C} 18$, the stereochemistry of the C9-C10 DB (E) could be deduced, and this was confirmed by identification of a singlet at $1.55 \mathrm{ppm}$ in the ${ }^{1} \mathrm{H}$ spectrum due to H18 (c.f. 1.69 ppm when the C9-C10 DB is Z; Belt et al., 2000). In contrast, the resonance attributed to C17 (18.3 ppm) is shifted to lower field compared to that of its counterpart with known $(E)$ stereochemistry 91 (11.8 ppm; Wraige et al., 1999), while the corresponding ${ }^{1} \mathrm{H}$ resonance $(\mathrm{H} 17)$ is also low field shifted (1.49 ppm) relative to the $E$ isomer (1.43 ppm; Wraige et al., 1999). Finally, the resonance for the alkenic proton H5 in I (5.14 ppm) is

94 low field shifted compared to the corresponding proton in II and to H9 in both (5.02 ppm). As such, the NMR data indicate that the stereochemistry of the

C5-C6 DB is $Z$ and we also provide chromatographic and mass spectrometric 
97 data in support of this assignment. Belt and Cabedo-Sanz (2015) demonstrated

98 that geometric isomers of $\mathrm{C}_{25} \mathrm{HBI}$ monoenes and dienes with $\mathrm{C} 5-\mathrm{C} 6 \mathrm{DB}$ are

99 well resolved by GC-MS, with $Z$ isomers eluting before their $E$ counterparts

100 and a difference in RI $(\Delta \mathrm{RI})$ of ca. 28. Significantly, therefore, the HBI triene

101 identified here $\left(\mathrm{I} ; \mathrm{RI}_{\mathrm{HP} 5 \mathrm{~ms}} 2075\right)$, elutes before the corresponding $E$ isomer

$102\left(\mathrm{RI}_{\mathrm{HP} 5 \mathrm{~ms}} 2103\right)$ with a $\Delta \mathrm{RI}$ of 28 . Finally, the mass spectrum of $\mathrm{I}$ is extremely

103 similar to that of II (Fig. 1), also consistent with observations made previously

104 for other HBI geometric isomers (Belt et al., 2000; Belt and Cabedo Sanz, 105 2015).

Although a much lower abundance in the purified fraction prevented us

107 from obtaining satisfactory ${ }^{13} \mathrm{C}$ NMR data, the structure of the co-occurring

108 HBI tetraene (III) can be proposed on the basis of related ${ }^{1} \mathrm{H}$ NMR and GC-

109 MS data to those found for triene I. Most notably, the ${ }^{1} \mathrm{H}$ NMR spectrum of

110 tetraene III confirmed the presence of only one isopropyl moiety (0.85 ppm),

111 two singlets due to H15 (1.65 ppm) and H19 (1.58 ppm), and two additional

112 allylic protons (compared to triene I) at ca. $2 \mathrm{ppm}$. The $Z$ stereochemistry of 113 the C5-C6 DB was again evident with characteristic resonances for H17 (1.49

$114 \mathrm{ppm})$ and H5 (5.15 ppm). An additional (compared to triene I) alkene proton 115 resonance provided evidence for a tri-substituted DB at C13-C14, while an 116 alternative location for this additional $\mathrm{DB}$ at $\mathrm{C} 2-\mathrm{C} 3$ can be discounted on the 117 basis of an absence of any double-allylic protons (i.e. H4) that would resonate 118 at ca. 2.8 ppm (e.g. Sinninghe Damsté et al., 1999). Further, the mass spectral 119 similarity between III (this study) and IV (Allard et al., 2001) (Fig. 1) and a 
$120 \Delta \mathrm{RI}$ of 28 are consistent with other $\mathrm{HBI}$ isomers with $E / Z$ isomerism at C5-C6

121 as described here and by others (Belt and Cabedo-Sanz, 2015).

122 Previously, HBIs containing C9-C10 DB with $Z$ stereochemistry have 123 been identified in cultures of a different strain of $P$. intermedium (Belt et al., 124 2000), and several other HBIs exhibiting $E / Z$ isomerism have been reported in 125 sediments and in laboratory rearrangement reactions (Belt and Cabedo-Sanz, 2015). Our new findings, however, represent the first example of biogenic HBIs possessing a C5-C6 DB with $Z$ stereochemistry. Finally, the organic carbon content of $P$. intermedium (14\%) and intra-cellular concentrations of HBI I (0.5 pg cell-1) and III (1 pg cell-1) are similar to those reported for other HBI-producing diatoms (Volkman et al., 1994; Belt et al., 1996; Grossi et al., 2004; Brown et al., 2014).

\section{Conclusions}

The structures of two previously uncharacterised $\mathrm{C}_{25} \mathrm{HBI}$ alkenes have been identified following laboratory culturing of the diatom $P$. intermedium and analysis of partially purified hydrocarbon extracts using NMR spectroscopy and GC-MS. This study adds to the existing suite of structurally characterised HBI alkenes and it will be interesting, in the future, to see if the same biomarkers can be identified in environmental or geochemical samples.

\section{Acknowledgments}

142 We thank the University of Plymouth for financial support and to Joe Curiale 143 for supportive feedback on the original manuscript. 
145 References

146 Allard, W. G., Belt, S.T., Massé, G., Naumann, R., Robert, J.-M., Rowland, S.J.,

147 2001. Tetra-unsaturated sesterterpenoids (Haslenes) from Haslea ostrearia 148 and related species. Phytochemistry 56, 795-800.

149

150 Belt, S.T., Cabedo-Sanz, P., 2015. Characterisation and isomerisation of mono-

151 and di-unsaturated highly branched isoprenoid (HBI) alkenes: considerations

152 for palaeoenvironment studies. Organic Geochemistry 87, 55-67.

153

154 Belt, S.T., Cooke, D.A., Robert, J.-M., Rowland, S.J., 1996. Structural

155 characterisation of widespread polyunsaturated isoprenoid biomarkers: $\mathrm{A} \mathrm{C}_{25}$

156 triene, tetraene and pentaene from the diatom Haslea ostrearia Simonsen.

157 Tetrahedron Letters 37, 4755-4758.

158

159 Belt, S.T., Allard, W.G., Massé, G., Robert, J.-M., Rowland, S.J., 2000. Highly 160 branched isoprenoids (HBIs): identification of the most common and abundant 161 sedimentary isomers. Geochimica et Cosmochimica Acta 64, 3839-3851.

162

163 Brown, T.A., Belt, S.T., Cabedo-Sanz, P., 2014. Identification of a novel di-

164 unsaturated $\mathrm{C}_{25}$ highly branched isoprenoid in the marine tube-dwelling

165 diatom Berkeleya rutilans. Environmental Chemistry Letters, 12, 455-460. 
167 Grossi, V., Beker, B., Geenevasen, J.A.J., Schouten, S., Raphel, D., Fontaine, M.-

168 F., Sinninghe Damsté, J.S., 2004. C 25 highly branched isoprenoid alkenes from

169 the marine benthic diatom Pleurosigma strigosum. Phytochemistry 65, 3049-

1703055.

172 Sinninghe Damsté, J.S., Schouten, S., Rijpstra, W.I.C., Hopmans, E.C.,

173 Peletier, H., Gieskes, W.W.C., Geenevasen, J.A.J., 1999. Structural

174 identification of the $\mathrm{C}_{25}$ highly branched isoprenoid pentaene in the marine

175 diatom Rhizosolenia setigera. Organic Geochemistry 30, 1581-1583.

176

177 Volkman, J.K., Barrett, S.M., Dunstan, G.A., 1994. $\mathrm{C}_{25}$ and $\mathrm{C}_{30}$ highly branched 178 isoprenoid alkenes in laboratory cultures of two marine diatoms. Organic 179 Geochemistry 21, 407-414.

180

181 Wraige, E. J., L. Johns, S. Belt, G. Massé, J.-M. Robert, and S. Rowland. 1999.

182 Highly branched $\mathrm{C}_{25}$ isoprenoids in axenic cultures of Haslea ostrearia.

183 Phytochemistry 51, 69-73.

185 Figures and Tables

186 Figure 1. (a) Partial GC-MS chromatogram of the hydrocarbon fraction

187 obtained from an extract of $P$. intermedium. (b) Structures and mass spectra of 188 HBI alkenes described in the text.

190 Table 1. NMR data for HBI I and III. (Note: ${ }^{13} \mathrm{C}$ NMR data for HBI I only) 
Figure 1

(a)

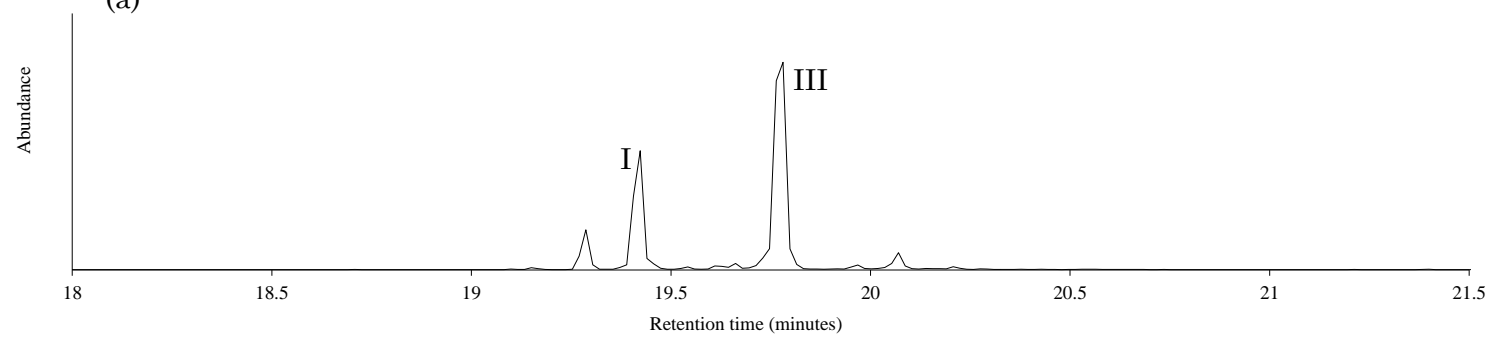

(b)
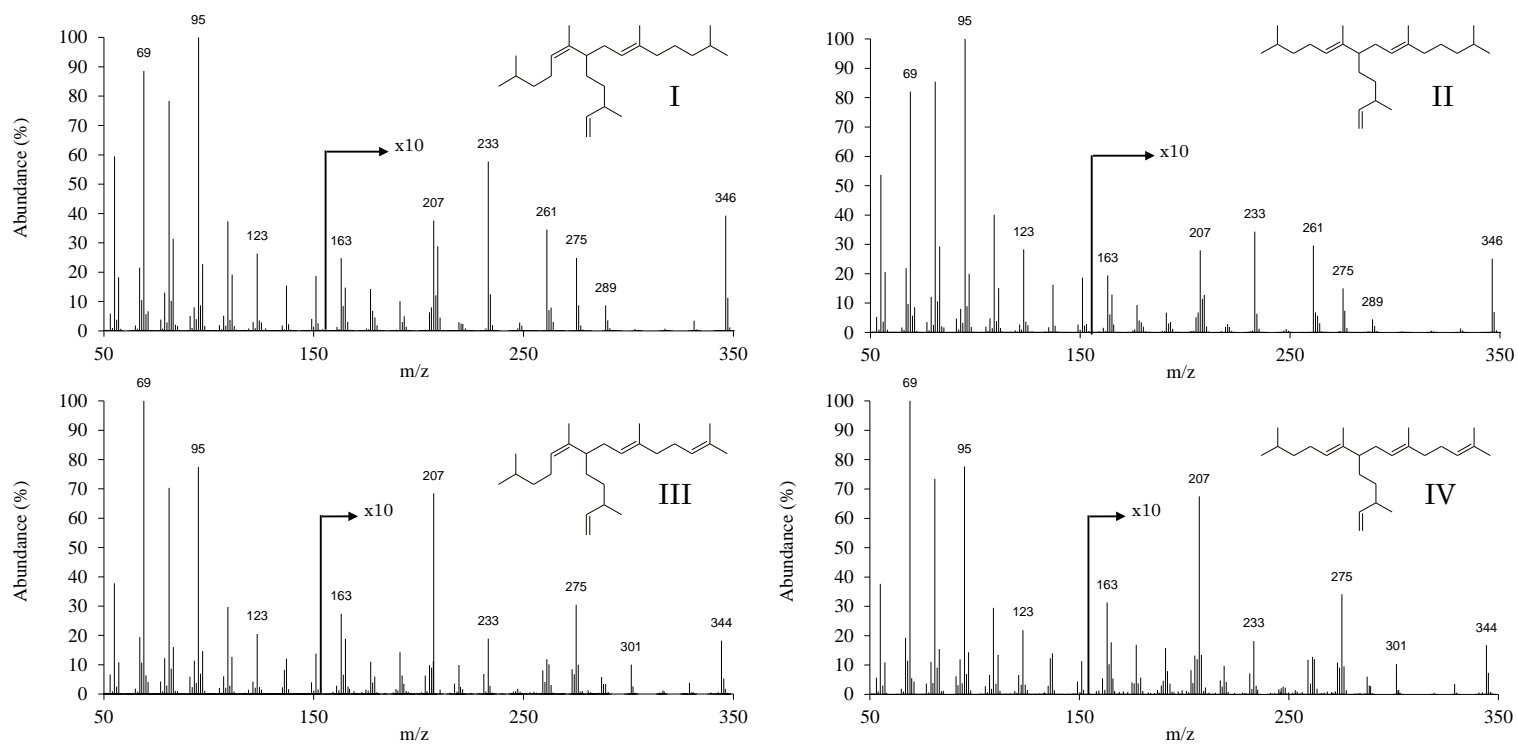
Disclaimer: This is a pre-publication version. Readers are recommended to consult the full published version for accuracy and citation.

\begin{tabular}{llll}
\hline Carbon number & $\begin{array}{l}\text { Carbon shift } \\
(\delta / \mathrm{ppm})\end{array}$ & Proton number & $\begin{array}{l}\text { Proton shift } \\
(\delta / \mathrm{ppm})\end{array}$ \\
\hline 1 & 22.6 & $\mathbf{C}_{25: 3}$ (HBI I $)$ & \\
2 & 27.7 & $1,15,16,19$ & 0.84 and $0.85(12 \mathrm{H}, 2 \mathrm{x} \mathrm{d}, J=7 \mathrm{~Hz})$ \\
3 & 38.6 & 25 & $0.94(3 \mathrm{H}, \mathrm{d}, \mathrm{J}=7 \mathrm{~Hz})$ \\
$4^{\mathrm{a}}$ & 25.4 & $2,3,12,13,14,20,21$ & $1.05-1.37(12 \mathrm{H}, \mathrm{m})$ \\
5 & 127.1 & 17 & $1.49(3 \mathrm{H}, \mathrm{s})$ \\
6 & 136.8 & 18 & $1.55(3 \mathrm{H}, \mathrm{s})$ \\
7 & 46.6 & $4,7,8,11,22$ & $1.87-2.08(8 \mathrm{H}, \mathrm{m})$ \\
8 & 32.2 & 24 & $4.89(2 \mathrm{H}, \mathrm{m})$ \\
9 & 123.2 & 9 & $5.02(1 \mathrm{H}, \mathrm{d}, J=7 \mathrm{~Hz})$ \\
10 & 134.3 & 5 & $5.14(1 \mathrm{H}, \mathrm{d}, J=7 \mathrm{~Hz})$ \\
11 & 40.1 & 23 & $5.63(1 \mathrm{H}, \mathrm{ddd}, J=17,10,7 \mathrm{~Hz})$ \\
$12^{\mathrm{a}}$ & 25.7 & & \\
13 & 38.6 & $\mathbf{C} 25: 4(\mathbf{H B I} \mathrm{III})$ & \\
14 & 27.7 & 1,16 & $0.85(6 \mathrm{H}, \mathrm{d}, J=7 \mathrm{~Hz})$ \\
15 & 22.6 & 25 & $0.94(3 \mathrm{H}, \mathrm{d}, J=7 \mathrm{~Hz})$ \\
16 & 22.6 & $2,3,20,21$ & $1.1-1.4(7 \mathrm{H}, \mathrm{m})$ \\
17 & 18.3 & 17 & $1.49(3 \mathrm{H}, \mathrm{s})$ \\
18 & 16.4 & 18 & $1.56(3 \mathrm{H}, \mathrm{s})$ \\
19 & 22.6 & 19 & $1.58(3 \mathrm{H}, \mathrm{s})$ \\
20 & 29.9 & 15 & $1.65(3 \mathrm{H}, \mathrm{s})$ \\
21 & 34.6 & $4,7,8,11,12,22$ & $1.86-2.06(10 \mathrm{H}, \mathrm{m})$ \\
22 & 38.6 & 24 & $4.89(2 \mathrm{H}, \mathrm{m})$ \\
23 & 144.9 & 9,13 & $5.05(2 \mathrm{H}, \mathrm{m})$ \\
24 & 112.5 & 5 & $5.14(1 \mathrm{H}, \mathrm{t}, J=7 \mathrm{~Hz})$ \\
25 & 20.5 & 23 & $5.63(1 \mathrm{H}, \mathrm{ddd}, J=17,10,7 \mathrm{~Hz})$ \\
\hline
\end{tabular}

${ }^{\text {a }}$ Resonances may be interchanged

Table 1 
Dr John Volkman

Editor, Organic Geochemistry

November 2015

Dear John

Please find attached a revised manuscript: "Novel tri- and tetra-unsaturated highly branched isoprenoid (HBI) alkenes from the marine diatom Pleurosigma intermedium" that addresses (accepts) all of the relatively small number of editorial changes requested by the reviewer (Joe Curiale, now acknowledged). Exceptionally, we have opted to remove the 'See Table 1' addition from the Figure 1 legend as these represent different data.

Regards,

Simon

Professor Simon Belt

University of Plymouth 